\title{
Contribuição do Projeto HOPE para a configuração da identidade profissional das primeiras enfermeiras alagoanas, 1973 a 1977
}

\author{
Project HOPE contribution to the setting up of the professional identity \\ of the first nurses from Alagoas, 1973-1977 \\ Contribución del Proyecto HOPE para la formación de la identidad profesional \\ de las primeras enfermeras alagoanas, 1973-1977
}

\author{
Laís de Miranda Crispim Costa', Regina Maria dos Santos', Tânia Cristina Franco Santos", \\ Maria Cristina Soares Figueiredo Trezza', Josete Luzia Leite" \\ ' Universidade Federal de Alagoas, Escola de Enfermagem e Farmácia, \\ Programa de Pós-Graduação em Enfermagem. Maceió-AL, Brasil. \\ "Universidade Federal do Rio de Janeiro, Escola de Enfermagem Anna Nery, Departamento de Enfermagem Fundamental, \\ Programa de Pós-Graduação em Enfermagem. Rio de Janeiro-RJ, Brasil.
}

\section{Submissão: 31-01-2013 Aprovação: 02-06-2014}

\section{RESUMO}

Estudo histórico-social cujo objetivo foi analisar a contribuição das enfermeiras norte-americanas do Projeto HOPE à configuração da identidade profissional das primeiras enfermeiras formadas em Alagoas, no período de 1973 a 1977. O referencial teórico foi o "Processo Civilizador" de Norbert Elias. As fontes primárias foram documentos oficiais e arquivos pessoais de 13 entrevistados via história oral temática; as secundárias foram autores da História do Brasil/Alagoas. A análise dos dados evidenciou que a configuração da identidade profissional das primeiras enfermeiras formadas em Alagoas foi um processo civilizador, com todas as nuances que compõem as relações de poder. Houve uma contribuição significativa da Enfermagem norte-americana. Entretanto o movimento de resistência a essa dominação foi muito forte, resultando num Curso que conseguiu aproveitar o avanço tecnológico e o prestígio trazido pelos Estados Unidos para construir uma Enfermagem singular, a partir do tecido social bordado neste encontro de tantas culturas diferentes.

Descritores: História da Enfermagem; Identidade Profissional; Docentes de Enfermagem.

\section{ABSTRACT}

Social-historical study conducted to examine the contribution of the American Nurses of Project HOPE to the configuration of the professional identity of the first trained nurses in Alagoas, in the period of 1973-1977. The theoretical framework was the "Civilizing Process" of Norbert Elias. Primary sources were official documents and personal files of 13 respondents by oral history; the secondary sources were authors of the History of Brazil/Alagoas. Data analysis showed that the configuration of the professional identity of the first trained nurses in Alagoas was a civilizing process, with all the nuances that make up the power relations. There was a significant contribution of American Nursing. However the movement of resistance to this domination was very strong, resulting in a Course that could take advantage of technological advancement and prestige brought by the United States, to build a unique Nursing from the social fabric embroidery at this meeting with so many different cultures.

Key words: History of Nursing; Professional Identity; Faculty of Nursing.

\section{RESUMEN}

Estudio socio histórico que objetivó analizar la contribución de las enfermeras del Proyecto Norte Americano HOPE para la formación de la identidad profesional de las primeras enfermeras formadas en Alagoas, en el período de 1973-1977. El marco teórico utilizado fue el "proceso de civilización" de Norbert Elias. Las fuentes primarias fueran los documentos oficiales y los archivos personales de los 13 encuestados por medio de la historia oral y los secundarios fueron autores de la Historia de Brasil/ Alagoas. El análisis de los datos mostró que la configuración de la identidad profesional de las primeras enfermeras formadas en Alagoas fue un proceso de civilización, con todos los matices que componen las relaciones de poder. Hubo una importante contribución de la Enfermería de los Estados Unidos de América. Sin embargo, el movimiento de resistencia a esta dominación fue muy fuerte, lo que resultó en un Curso que tomó ventaja de los avances tecnológicos y del prestigio planteado por los Estados Unidos, para construir una Enfermería única a partir del tejido social bordado en el encuentro de culturas tan diferentes. Palabras clave: Historia de la Enfermería; Identidad Profesional; Facultad de Enfermería.

\section{AUTOR CORRESPONDENTE Laís de Miranda Crispim Costa E-mail: laismcc@gmail.com}




\section{INTRODUÇÃO}

Este estudo tem como objeto a contribuição das enfermeiras norte-americanas do Projeto HOPE à configuração da identidade profissional das egressas da primeira turma do curso de Graduação em Enfermagem da Universidade Federal de Alagoas UFAL. Este foi o primeiro Curso de Graduação em Enfermagem no estado, ano em que o Projeto HOPE (Health Opportunity for People Everywhere), funcionando a bordo de um navio hospital, permaneceu atracado no porto de Maceió - capital do estado - através de um convênio entre o governo do estado, o Projeto HOPE e a UFAL. Dentre os objetivos da vinda deste navio, ressalta-se o ensino das mais recentes técnicas da ciência médica norte-americana e a atuação dos profissionais no atendimento de casos de saúde de interesse científico para as partes ${ }^{(1)}$.

As enfermeiras norte-americanas atuavam em Maceió, capital do estado, como contraparte das primeiras enfermeiras docentes, inclusive Vera Rocha, primeira coordenadora de Enfermagem do Hospital Universitário da UFAL. Continuaram atuando como apoio ao curso criado ao lado das enfermeiras docentes, principalmente nas atividades práticas, por esta razão tem-se a hipótese de que essas enfermeiras contribuíram para a configuração da identidade profissional das enfermeiras formadas em Alagoas no recorte temporal em estudo.

Por outro lado, as demais enfermeiras docentes vieram de vários estados brasileiros, pois até então, Alagoas não contava com nenhum Curso de Graduação em Enfermagem, existindo apenas a Escola de Auxiliares de Enfermagem de Alagoas - EAEA criada no ano de 1952 com a intenção de implantar também um curso de nível superior, fato que não aconteceu ${ }^{(2)}$. Portanto, em relação à categoria de enfermagem até aquele momento, os serviços de saúde do estado contavam com poucas enfermeiras e majoritariamente com atendentes e auxiliares de enfermagem. As enfermeiras do Projeto HOPE contribuíram para reconfigurar este cenário.

Neste trabalho, o termo configuração deve ser entendido como uma cadeia de interdependência entre indivíduos que podem variar na temporariedade e complexidade, mas que determinam a mobilidade, formação ou mesmo reprodução social, onde cada indivíduo em particular têm suas intenções, no entanto as transformações históricas dependem da relação indissociável entre este e a sociedade ${ }^{(3)}$, tal como defende Norbert Elias, referencial teórico que sustenta esta pesquisa.

A ideia de configuração ajudou a entender como ocorreu o processo de composição do corpo docente na época de criação do curso de Graduação em Enfermagem da UFAL, período em que aconteceu um encontro de diferentes culturas, visto que todas as enfermeiras que vieram fazer parte deste curso se formaram em outros estados e a grande maioria também era natural de várias cidades do Brasil, fazendo construir no micro espaço alagoano um novo tecido social da Enfermagem. Assim, ao realizar estudos históricos a partir da "configuração" proposta por Elias, pode-se construir novos caminhos para compreender as estruturas sociais no recorte geográfico local. Isso porque a configuração seria uma abrangência relacional, o modo de existência do ser social e a possibilidade de aproximação às emergências do cotidiano ${ }^{(3)}$.
Com a chegada do navio HOPE no porto de Maceió em fevereiro de 1973, Alagoas passa a conhecer outra cultura de enfermagem, pautada no modelo anglo-americano vigente nos EUA na década de 70, caracterizado pela atuação de uma Enfermagem independente, científica e altamente resolutiva, representado pelas enfermeiras que faziam parte deste projeto e que aqui permaneceram até o mês de novembro do mesmo ano.

O trabalho destas enfermeiras, a expansão dos Cursos de Graduação em Enfermagem no Brasil, o processo de expansão da UFAL na época e a visão do Reitor Nabuco Lopes conformaram o momento favorável para criação do Curso de Enfermagem da UFAL ${ }^{(1,4-5)}$. Nesta conjuntura, este estudo tem como objetivo: analisar a contribuição das enfermeiras norte-americanas pertencentes ao navio HOPE à configuração da identidade profissional das egressas do primeiro Curso de Graduação em Enfermagem de Alagoas.

\section{METODOLOGIA}

Estudo de cunho histórico-social, com abordagem qualitativa. O recorte social e temporal foi o município de Maceió, no período compreendido entre 1973 e 1977, tendo como marco inicial a notícia oficial de criação do curso e como marco final a formatura da primeira turma em junho de 1977. As fontes primárias foram os documentos oficiais do Arquivo Central, da Coordenação do Curso de Enfermagem e do Conselho Universitário da UFAL, os documentos resultantes da transcrição de 13 entrevistas de professores e colaboradores, bem como seus arquivos pessoais (certificados, portarias e outros documentos).

Os critérios de inclusão dos sujeitos foram: ter pertencido ao corpo docente do curso no recorte temporal em estudo; ter participado da organização e funcionamento do curso; ter aceitado participar do estudo e ter sido citado como participante por outro depoente. Teve apenas um critério de exclusão, qual seja, estar impossibilitado por qualquer razão de conceder entrevista. As fontes secundárias foram compostas por autores que abordam a História do Brasil e de Alagoas que compuseram a conjuntura do estudo.

Para a fase de organização das informações reunidas, os documentos foram submetidos à análise interna e externa, separando-os primeiramente pelas categorias 'documentos oficiais' e 'documentos não oficiais'. A análise externa se preocupou com a autenticidade do documento, ou seja, se o texto era original ou cópia, qual a procedência ou autoria; já a análise interna objetivou a avaliação do peso e valor das provas, isto é, do seu conteúdo, buscando apreender o significado da declaração dentro do documento e determinar sua autenticidade e fidedignidade.

A análise e a discussão dos achados foram orientadas pela teoria do "Processo Civilizador" de Norbert Elias, que tem como fundamento o estudo dos efeitos do desenvolvimento de estruturas sociais sobre os costumes e a moral dos indivíduos ${ }^{(6)}$.

Vale enfatizar que os entrevistados autorizaram a utilização de seus depoimentos através da assinatura do termo de consentimento livre e esclarecido - TCLE e que, além disto, preferiram usar seus próprios nomes, abrindo mão da preservação 
de sua identidade nesta pesquisa, revelando a importância de dar voz ao sujeito, identificando quem fala, de qual posição fala e para quem fala. Todos os depoimentos colhidos neste estudo foram cedidos ao Grupo de Estudos D. Isabel Macintyre, onde o estudo está registrado. Para atender à Resolução 196/96 do Conselho Nacional de Saúde, o projeto foi submetido ao Comitê de Ética em Pesquisa com Seres Humanos da UFAL, sendo aprovado como consta no processo de $\mathrm{n}^{\circ}$ 23065.015735/2011-40.

\section{RESULTADOS E DISCUSSÃO}

Para Norbert Elias, o Processo Civilizador constitui-se em um movimento abrangente de crescente diferenciação nas relações sociais e que se mantém em progressiva expansão, através da incorporação de novos territórios e classes a uma rede de interdependência políticas e econômicas, manifestada pela autoconfiança de povos cujas fronteiras e identidade nacional foram plenamente estabelecidas séculos atrás, povos estes que se expandiram e colonizaram (ou civilizaram) outros povos ${ }^{(6)}$.

Neste estudo, a analogia está nas contribuições que as enfermeiras dos Estados Unidos que estavam prestando serviços filantrópicos no navio HOPE trouxeram para uma instituição pública de ensino universitário que estava implantando um Curso de Graduação em Enfermagem num estado do nordeste brasileiro, de precárias condições de saúde, cuja cultura do trabalho de enfermeiros ainda não era expressiva. A análise dos documentos e dos depoimentos revelou que a cultura de enfermagem norte-americana influenciou o curso em duas circunstâncias, como se poderá ver:

\section{A influência norte-americana nos bastidores de criação do curso de Enfermagem da UFAL}

Até 1973, a UFAL só contava com dois cursos da área da saúde, Medicina e Odontologia ${ }^{(7)}$. Com isso, o fato de chegar a Alagoas uma Enfermagem exercida por enfermeiras graduadas que tinham alto prestígio, lideravam os setores e contavam com um avançado aparato tecnológico causou impacto no cenário alagoano, inclusive na universidade, pois o navio-escola-hospital HOPE serviu de campo de estágio para os acadêmicos de medicina e odontologia na época.

$O$ reduzido número de enfermeiras na cidade foi claramente notado pelas enfermeiras do HOPE. A depoente norte-americana Bárbara relata como as enfermeiras do Projeto HOPE viam a necessidade de enfermeiras locais liderarem os setores:

Junto com todos os avanços tecnológicos a gente viu a necessidade da pessoa de uma enfermeira de nível superior começando a liderar os setores. (Bárbara)

Nesse contexto, a cultura de enfermagem norte-americana, representada por essas enfermeiras, tratou de se impor no micro espaço alagoano de várias formas. Uma delas era a metodologia sistematizada de cuidar que as enfermeiras empregavam, expressando a premência de haver enfermeiras nos serviços e de que elas evidenciassem seu potencial de trabalho. Assim, tentaram introduzir no cenário alagoano esta metodologia, que chamavam de Processo de Enfermagem. Para tanto, além de exercê-lo na prática, promoveram seminários para capacitar docentes e enfermeiras chefes de instituições nordestinas, como consta no livro-programa de um seminário realizado pelas enfermeiras do navio para ensinar sua metodologia de trabalho.

Um destes seminários aconteceu nos dias 11 e 12 de maio de 1973, contando também com a participação de enfermeiras que ocupavam cargos importantes, como a presidente da Associação Brasileira de Enfermagem Seção Alagoas, professora Verônica Belmiro Chaves Donato, a diretora da Faculdade de Enfermagem da Universidade Federal de Pernambuco, professora Desdemona Aurea Bezerra Fernandes, e a Chefe do Serviço de Enfermagem do Hospital Agamenon MagaIhães do Recife, professora Maria Luiza Munguba ${ }^{(8)}$, fato que demonstrava a articulação do HOPE com as instituições locais e regionais de enfermagem.

No livro programa deste seminário consta que a proporção de enfermeiras por habitantes no Brasil era de 1 para cada 11.500 pessoas, em contrapartida os EUA, nesta época, já contava com 1 enfermeira para cada 200 habitantes $^{(8)}$. Na verdade, $70 \%$ do pessoal de enfermagem do Brasil estavam constituídos por atendentes de enfermagem, o que faz presumir que em Alagoas a situação era ainda mais alarmante, visto que não existia nenhuma Escola de Graduação no Estado.

As enfermeiras que ministraram este seminário colocavam que esta realidade era causada pelo "baixo salário, falta de estímulo à profissão e falta de status social da profissão"(8). Estas mesmas razões impediam o crescimento da profissão, pois as poucas enfermeiras diplomadas, como elas mesmas chamavam, praticamente só exerciam cargos de chefia, deixando de lado o cuidado direto ao paciente, o que prejudicava a valorização da profissão, pois esta, só conseguiria se estabelecer dependendo da competência da enfermeira em usar o processo de enfermagem $(\mathrm{PE})^{(8)}$.

Em contrapartida, o Projeto HOPE, já no início da década de 1970 traz um livro-programa com esta denominação, demonstrando que a cultura de enfermagem sobre o PE era algo consolidado entre elas, o que comprovamos pelos diversos estudos teóricos sobre modelos de enfermagem que foram criados nos EUA desde a década de $1920^{(9)}$. A depoente Lúcia também expressa como os professores, que compuseram o corpo docente do curso, reconheciam a experiência destas enfermeiras:

E elas eram experientes, tinham com elas a metodologia da assistência, estavam na frente da gente há algum tempo. Mas teve coisas boas e teve também problemas. (Lúcia Leite)

Neste depoimento também se percebe manifestações de resistências da imposição desta cultura de enfermagem. Leve-se em conta que os EUA se consideravam um povo de desenvolvimento e cultura mais evoluídos e que praticavam uma política assistencialista de boa vizinhança ${ }^{(5)}$, através da qual impunham uma cultura aceita, social e historicamente, como "superior", sobre uma considerada inferior, representada aqui pela Enfermagem alagoana. Norbert Elias explica como tal fenômeno se desenvolve: 
Duas etapas fazem parte da propagação do processo civilizador, a de assimilação e repulsão. Na primeira, os indivíduos sobem da classe mais baixa para a superior, e esta tenta civilizar a classe considerada inferior, que por sua vez tende a copiar a classe evoluída. Em consequência desta primeira etapa, o poder perante a sociedade do grupo inferior aumenta e declina o do grupo superior, por isso denomina-se assimilação, todavia este processo acentua cada vez mais as diferenças entre os dois grupos, concretizando uma segunda etapa denominada repulsão, onde a rivalidade aumenta, consolidando a distância que existe entre ambas ${ }^{(3)}$.

Assim, todo este processo interessou sobremaneira aos EUA, pois seus objetivos de cultura imperialista eram que suas práticas fossem incorporadas, no nosso caso, a cultura de enfermagem norte-americana, como também a reafirmação dos contrastes entre as classes. A professora Vera Rocha deixa claro como o povo estadunidense via os nordestinos como representantes de uma cultura inferior.

Imagina os Estados Unidos para o Brasil [...] tinha pessoas com essas características, que via os brasileiros, os nordestinos [...] como não diria... uma sub raça. (Vera Rocha)

Essa trama acontece de forma tão dinâmica que não se consegue perceber como os indivíduos têm que reprimir a si mesmo e a sua espontaneidade para colocar em prática um comportamento imposto, considerado mais civilizado. Ainda assim, a enfermeira e professora Lenir Nunes, que ingressou na UFAL em setembro de 1973, quando o navio HOPE ainda estava em solo alagoano, coloca como via essa interferência dos EUA:

E o pessoal do HOPE, minha filha, tenha santa paciência, só pra brasileiro mesmo não entender que aquele navio não veio pra cá só pra trazer beneficio. Ele veio pra levar o que a gente tinha pra lá. (Lenir)

Outra depoente também lembra como a categoria médica via a presença dos EUA, enfatizando a admiração inclusive pelas enfermeiras:

E aí o que era que os famosos catedráticos tinham? Admiração profunda pelos Estados Unidos da América, né? As enfermeiras[...], mas nós nunca deixamos a desejar. (Zandra)

Ocorre que naquela época a profissão que detinha o controle dos serviços de saúde em Alagoas era a medicina, e o outro curso que existia em Alagoas na área da saúde era o de odontologia, que pouco interferia na hegemonia médica. Então, uma coisa eram as enfermeiras que faziam parte de um projeto que tinha início, meio e fim, outra era a iniciativa de criação de um Curso de Graduação em Enfermagem que se consolidaria na UFAL e ditaria as regras de atuação da Enfermagem no cenário alagoano.

A autorização para o funcionamento do curso aconteceu no dia $1^{\circ}$ de novembro de 1973 , em reunião do Conselho de Ensino e Pesquisa da UFAL ${ }^{(10)}$, e neste momento o navio
HOPE ainda estava atracado no porto de Maceió. Vale ressaltar que nesta fase a professora Vera Rocha foi nomeada como docente através de concurso público, mas já atuava anteriormente como a primeira enfermeira contratada da UFAL, desenvolvendo suas atividades na Santa Casa de Misericórdia de Maceió, hospital que exercia o papel de Hospital Universitário - HU, tendo como contraparte a coordenadora de enfermagem do navio HOPE, enfermeira VeNeta Masson ${ }^{(5)}$. Vera Rocha, representava na UFAL o primeiro exemplo da cultura de enfermagem brasileira em Alagoas. Quando o HU foi transferido para a Cidade Universitária, Vera Rocha se tornou sua primeira coordenadora de enfermagem.

Analisando o contexto da época, a forma de composição do primeiro corpo docente teve uma dinâmica interessante, que se estendeu para além da formatura da primeira turma. Para Norbert Elias, a noção de configuração supera as ações individuais, pois permite a formação de um tecido social, onde cada pessoa pertencente a esta trama tem suas particularidades, mas que só podem ser compreendidas nas relações que se estabelecem. Ou seja, apesar da imposição da cultura de enfermagem norte-americana, trazida pelas enfermeiras do navio HOPE, o que se configurou no processo de criação e consolidação do primeiro Curso de Graduação em Enfermagem de Alagoas foi uma interdependência de pessoas, com movimentos de assimilação e repulsa, que contribuiu para a configuração da identidade profissional das egressas deste curso.

Contribuição das enfermeiras norte-americanas na configuração da identidade profissional das primeiras enfermeiras formadas em Alagoas

Como a forma de composição do corpo docente foi muito diversificada, o Curso de Graduação em Enfermagem foi o cenário de configuração social no qual se estabeleceram relações de interdependência entre os vários atores deste recorte temporal, onde os desdobramentos desta trama de pessoas contribuíram para a construção da identidade profissional das egressas do curso, "isto porque as estruturas da personalidade e da sociedade evoluem em uma inter-relação indissolúvel"(6).

As alunas da primeira turma sofreram as influências de todos os envolvidos no processo, mas também exerceram influência sobre estes, visto que traziam consigo um ideal de enfermeiro pertencente ao ciclo social do qual faziam parte. Os três primeiros grupos que vieram compor este corpo docente eram os médicos, as enfermeiras do navio HOPE e as professoras enfermeiras Vera Rocha e Lenir Nunes.

A Professora Lenir não estava alinhada com estes outros atores, pois trazia uma cultura de enfermagem que aprendera no Rio de Janeiro, local onde se formara, centro de nascimento do modelo nightingaleano no Brasil. Lenir representava uma primeira resistência à imposição da cultura de enfermagem norte-americana e da cultura de enfermagem trazida pelos médicos alagoanos. Depois de mais de um ano de funcionamento do curso, o corpo docente recebe enfermeiras de vários estados brasileiros, da Bahia, do Maranhão e do Pará, e já no ano de formatura da primeira turma, ganha enfermeiros formados no Rio de Janeiro e no Recife. 
Segundo a Professora Lenir, as primeiras dificuldades encontradas se deram logo após a criação do curso, momento de maior interferência das enfermeiras norte-americanas. Possivelmente Vera Rocha, que passou a fazer parte da equipe do navio HOPE, contava com o reforço das enfermeiras americanas para colaborar nas atividades do curso recém-criado. Tal suposição se mostrou consistente, uma vez que, além da participação dos docentes médicos, o curso efetivamente contou com a participação do Projeto HOPE, sobretudo pela relação, inclusive de amizade, com a professora Vera Rocha, como Lenir afiançava.

\section{Ela [Vera] era muito amiga do pessoal do HOPE [...]. (Lenir)}

Nesta fase, as alunas do curso praticamente só tinham contato com os professores médicos e com a professora Vera Rocha, então coordenadora do curso. Não obstante, logo o período do ciclo básico se encerraria e era preciso planejar o andamento do curso. Neste sentido, a professora Lenir, analisando a conjuntura desenhada naquele espaço social e o desenho da grade curricular que encontrara, já manifestava sua preocupação em imprimir ao curso criado uma identidade de curso de enfermagem.

Olha, minha gente, eu vim aqui para o curso de enfermagem, para ser enfermeira [...] enfermicina de jeito nenhum. (Lenir)

É possível perceber claramente um choque entre três culturas de enfermagem: a dos médicos - de uma profissão meramente auxiliar -, a das enfermeiras norte-americanas - altamente técnico-científica - que já havia influenciado Vera Rocha, ainda recém-formada e a de Lenir, com mais tempo de formada em escola consolidada no Rio de Janeiro e com visão de enfermagem mais abrangente e combativa no trato das questões políticas da saúde e da autonomia da profissão.

Estes embates acabam se configurando como relações de poder, que para Norbert Elias, são positivas uma vez que propiciam a formação social e individual de pessoas, grupos ou instituições. Ou seja, se por um lado este sistema instala a diferença entre as pessoas, por outro organiza e dá direcionalidade ao contexto ${ }^{(11)}$. Assim, a cultura trazida pelos docentes deve ser vista como uma estrutura de mudança dinâmica e constante que sem dúvida influenciou na identidade profissional dos formandos deste curso.

Visualizam-se, nesta primeira etapa do curso, três movimentos em torno do ensino da Enfermagem que certamente repercutiram nas alunas. O primeiro manifesta-se pela desarticulação do ciclo básico com o clico profissionalizante, no qual os professores ministravam suas aulas para todos os alunos da área da saúde, independente de curso. O segundo se refere a imposição da cultura de enfermagem norte-americana, representada pela atuação das enfermeiras do Projeto HOPE, que foi bem acolhida e aceita pela professora Vera Rocha. E o terceiro se dá pelo movimento de resistência da professora Lenir no que tange a atuação da categoria médica no curso e a imposição da cultura de enfermagem norte-americana sobre o mesmo.
As funções de cada pessoa dentro de um determinado cenário são diferentes e à medida que se configura como competição tornam-se cada vez mais diferenciadas, gerando um ciclo, onde, ao tempo em que cresce o número de atribuições de cada um, maior se torna a interdependência entre os mesmos, formando um tecido social dinâmico. Portanto, pode-se dizer que os resultados a longo prazo são praticamente não idealizados individualmente, visto que faz parte de um processo maior, advindo de um entrelaçamento social. Obviamente as motivações individuais estão presentes, neste caso o papel de cada docente que fez parte do curso, no entanto as configurações sociais são consequências inesperadas da interação entre eles ${ }^{(3)}$.

Com isso, o Curso de Graduação de Enfermagem se configurou como um espaço de interação entre vários docentes e alunas, cada um representando uma cultura pessoal e de enfermagem. Esta rede de interação social não se refere apenas ao somatório dos interesses de cada um, mas resulta em um novo processo de configuração social, onde as intenções particulares perdem o seu valor.

Este emaranhado possibilitou a junção de várias visões de mundo e o encontro de diferentes culturas de enfermagem, configurando no cenário alagoano a inserção do ensino de graduação. Para a professora Heliana este processo foi tão relevante que causou notável mudança, muito provavelmente pela inserção de uma Enfermagem também científica, mas, também altamente politizada.

Que o fato de ter vindo de cada canto criou uma [...] uma possibilidade de a gente fazer uma coisa nova, a gente teve mais chance de começar com mais liberdade, sem estar atrelado a uma orientação só, a coisas mais rígidas de uma escola mais antiga. Então eu acho que a gente revolucionou um pouquinho algumas coisas aqui [...] Então eu acho que foi bom, não foi ruim essa miscelânea de cada canto. (Heliana)

A fala da professora Lígia é emblemática pata esta temática, pois conclui que a possibilidade de encontrar o novo e provocar mudanças é muito maior na diversidade do que na unanimidade:

Na diversidade você tem muito mais possibilidade de criar do que na unidade. Porque a diversidade cria discussões. (Lígia)

Fica também evidente a riqueza cultural advinda da interdependência dessas pessoas, onde os docentes precisaram se rearranjar para dar continuidade às atividades inerentes ao curso, cada um trazendo uma bagagem cultural de enfermagem significativa para o contexto que resultaria em uma nova identidade profissional de enfermagem no espaço alagoano.

Norbert Elias considera que isoladamente o conceito de cultura é excludente e delimitador, todavia as "construções de identidades culturais são muito importantes para a diferenciação das nações e das regiões, pois apontam para as questões 
da diferença e salientam o que há de específico e de particular entre os povos ou entre grupos"(12). Assim, logo que o curso passou a contar com um número significativo de pessoas para conduzir as disciplinas ocorreu um choque de ideias e não poderia ser diferente, pois cada um tinha um ideal de enfermeiro que seria formado neste curso. Nesse sentido, a professora Cristina colocou sua preocupação em relação à necessidade de se identificar com o curso ora criado:

Então a gente precisava ter uma identidade assim, mais da Enfermagem para o curso, e não algo que fosse baseado no que era legal, no que era mínimo. (Cristina)

À medida que os docentes começavam a se integrar fica mais evidente o encontro de diversas culturas, inclusive da cultura de enfermagem norte-americana:

Então a gente encontrou a Barbara, americana que pensava de um jeito, Vera Rocha que era alagoana formada em Recife que tinha outra forma de ver a formação do enfermeiro, Lenir que é formada na Universidade Federal Fluminense, não era novinha, ela já tinha experiência de trabalho, então ela tinha outra visão e nós três [...] três recém-formadas vindas de uma escola altamente tradicional. (Regina)

Partindo do pressuposto de que a primeira turma de enfermeiras formadas teve uma identidade profissional própria, construída a partir deste entrelaçamento de culturas, os depoimentos fizeram entender que os interesses individuais ou até mesmo coletivos se perderam nesta trama, ou seja, "vários fatores de ordem individual e coletiva interagem para produzir processos civilizadores que ganham movimento e se autoalimentam trazendo modificações significantes que configuram determinadas civilizações"(13).

Além das diversas culturas de enfermagem brasileiras trazidas pelas docentes a partir de sua escola de formação e área de atuação, durante um bom tempo o curso continuou contando com a participação das enfermeiras norte-americanas, na manutenção do projeto em terra, como nos recorda Bárbara, que permaneceu em Maceió após a partida do navio em novembro de 1973 :

Quando o navio HOPE foi embora, você já sabe, obviamente deixou as pessoas aqui na terra [...] se não me engano foram 5 enfermeiras exatamente, foi eu, a enfermeira Irene, July, Sheila e Beverly, e nós decidimos ficar [...] Então a gente ficou aqui, nosso contrato era na verdade, por que nessa época lembro que a gente estava ainda pelo Projeto HOPE, dando assistência a Universidade Federal de Alagoas. (Bárbara)

O depoimento da professora Regina mostra um exemplo claro da participação do Projeto HOPE na estrutura do Curso de Enfermagem:

Nós tentávamos construir estratégias de sobrevivência! Não podíamos negar a supremacia americana nos aspectos técnicos e tecnológicos, mas tentávamos mostrar que também tínhamos conhecimento de enfermagem e que estávamos à altura do desafio de ser docente daquele curso. Uma forma era unir o útil ao agradável: aprendíamos os aspectos que precisávamos e no processo mostrávamos o que sabíamos. Fazíamos isso nos mini cursos que organizávamos com as enfermeiras do HOPE, por exemplo, mas ganhávamos sempre os embates políticos estruturais. (Regina)

Outra pessoa que também atuou no curso representando uma posição de forte resistência a imposição da cultura de enfermagem norte-americana foi a professora Lígia, que ingressou no corpo docente em 1975 e logo em seguida tornou-se coordenadora do curso, exercendo liderança reconhecida por todos do grupo. O seguinte trecho de seu depoimento deixa claro este entendimento:

Eu nunca aceitei a interferência do HOPE no Curso de Enfermagem. (Lígia)

A professora Lígia esclareceu que ela tinha compromisso com o desenvolvimento da Enfermagem, onde quer que estivesse. Ela tinha um projeto de "enfermeiros" para este curso bem definido, só que, por baixo desta trama, coexistem acordos cumulativos concretizando uma ligação funcional que mistura os interesses individuais e os projetos coletivos resultando em instituições sociais, a que podemos denominar de redes de interação social ${ }^{(13)}$.

Com base nesta reflexão da teoria elisiana, pode-se dizer que todos os docentes envolvidos tinham uma proposta para formar as enfermeiras do curso recém-criado, no entanto, os movimentos de imposição e resistência das diversas culturas é que contribuíram para configurar a identidade profissional das suas egressas. No exercício desta resistência e por ocupar uma posição de líder perante as outras professoras, Lígia procurou seguir os caminhos legítimos dentro da universidade. Os grupos que se juntaram a ela o fizeram por se sentirem representados, por defenderem as mesmas ideias, sobretudo no que se refere à formação profissional do enfermeiro, tornando-se um grupo coeso para atender a necessidade colocada, que era construir o perfil do enfermeiro egresso daquele curso.

É possível afirmar que o movimento de imposição e resistência por parte das várias culturas de enfermagem pôde causar certo desgaste no tecido social instaurado, tão necessário para a incorporação da identidade profissional nas alunas. Isto porque as alunas também exerciam influência sobre este corpo docente, na medida em que se socializavam com a profissão escolhida e também assumiam uma posição questionadora perante o grupo de professores, escolhendo o caminho que queriam seguir.

Não tem como negar a contribuição que a Enfermagem norte-americana trouxe para as atividades práticas. Era através do sistema de contraparte que cada professor estabelecia parceira com uma enfermeira estrangeira, que já tinha muita habilidade com o manejo de equipamentos sofisticados. Nesta relação, as contribuições fluíram como Lígia explica: 
Então é [...] na realidade o pessoal do HOPE eles influenciaram mais, quer dizer ajudaram as recém-formadas a concretizar a parte clínica, só. [...] eles ajudaram sim, na parte técnica direcionada para o adulto, pra questão lá da cirurgia, da assistência disso, daquilo e daquilo outro. (Lígia)

A fala de Lígia confirma como as enfermeiras norte-americanas se envolveram e ajudaram principalmente as recém-formadas, mas sem interferir na cultura da Enfermagem brasileira que o curso imprimia aos alunos. Muito pelo contrário, o corpo docente soube aproveitar não só a tecnologia importada, como também o prestígio que a enfermagem norte-americana tinha na área, sobretudo perante a categoria médica.

O diário de campo da enfermeira do navio HOPE, VeNeta Masson, publicado em livro (International Nursing - VeNeta Masson, R.N. with contributors), traz um relatório no qual ela propõe oitos objetivos a serem implementados para melhorar a qualidade da assistência de enfermagem do HU e oferecer cuidados de enfermagem eficazes. O objetivo número sete deste documento diz que a Enfermagem, como uma profissão independente, tem que ser reconhecida, respeitada e ocupar um lugar de maior valor dentro daquele hospital.

Como este fato se refere ao período de 1973 a 1977, as enfermeiras professoras já haviam chegado e começaram as atividades práticas no $\mathrm{HU}$, alguns destes objetivos já tinham sido alcançados, de modo que os médicos já tinham tido contato com esta 'enfermagem independente'. Nesse sentido, as docentes souberam valer-se desta situação sem abrir mão da sua própria cultura de enfermagem que, no que se refere à autonomia da profissão, em nada deixava a desejar.

Ainda assim, os Estados Unidos, através das enfermeiras do navio, representavam uma cultura de enfermagem aceita mundialmente como superior, dando a conotação de que estariam fazendo um processo civilizador no Brasil, e talvez estivessem. Só que encontrou, no Curso de Enfermagem, enfermeiras com uma formação também muito sólida, talvez não tão avançada tecnologicamente, mas certamente com uma postura aguerrida. A depoente Lúcia traz uma fala que retrata esta compreensão:

Porque como eles conheciam as enfermeiras americanas do HOPE, eles também estagiaram no HOPE, eles viam o trabalho da enfermeira, o quê que elas faziam. Mas agente também contestava quando eles queriam colocar a gente pra baixo, vamos dizer assim, né? Nós também contestávamos porque [...] através de quê que a gente fazia isso? Conhecimento, do conhecimento, da prática. (Lúcia Leite)

Desta forma, as configurações sociais acabam determinando as ações individuais, fazendo com que se internalizem as regras de convivência e se modifiquem os hábitos, costumes e cultura. Se por um lado este processo significa um profundo autocontrole dos sujeitos, por outro propicia diversas possibilidades de estabelecimentos de redes de interação. Em outras palavras, “o comportamento social é ajustado de acordo com as necessidades impostas pelas percepções e interpretações que o indivíduo faz do ambiente externo"(13).

Esta reflexão faz compreender que, todos os indivíduos que atuaram para a formação das alunas da primeira turma do curso de enfermagem, contribuíram significativamente para a configuração de sua identidade profissional. Ora precisaram reprimir seus impulsos, pelo movimento de autocontrole, ora tiveram que se impor para serem reconhecidos no cenário social que estavam inseridos.

\section{CONCLUSÃO}

Este trabalho tratou da contribuição das enfermeiras do navio Projeto HOPE à configuração da identidade profissional da primeira turma de enfermeiras formadas na Universidade Federal de Alagoas. Para responder aos objetivos da pesquisa, foi preciso compreender como se deu a composição do primeiro corpo docente e de que maneira o grupo se rearranjou no cenário alagoano, visto que as enfermeiras norte-americanas tentaram impor sua cultura de enfermagem às professoras enfermeiras que vieram de vários estados brasileiros, cada uma com sua cultura pessoal e de enfermagem.

Os documentos escritos e orais permitiram dizer que as enfermeiras do navio HOPE, tanto quanto o corpo docente, deixaram uma contribuição fundamental para que o tecido social bordado por aquele grupo, com traços culturais, pessoais e de enfermagem tão diferentes, configurasse a identidade profissional das egressas à altura da necessidade social em Alagoas.

A influência da cultura de enfermagem norte-americana foi muito marcante no curso, no entanto o movimento de resistência a essa dominação foi muito forte, tendo como resultado um curso que conseguiu aproveitar o avanço tecnológico trazido pelos Estados Unidos, mas também construiu uma Enfermagem singular, resultante dessa miscelânea cultural. As contribuições das enfermeiras do navio HOPE aconteceram tanto nos bastidores da criação do curso como na fase de consolidação do mesmo, até a formatura da primeira turma, momento em que foram homenageadas e homenagearam, inclusive premiando a melhor aluna da turma (comportamento típico da cultura estadunidense).

Por esta razão, a configuração da identidade profissional das primeiras enfermeiras formadas em Alagoas foi um processo civilizador, com todas as nuances que compõem as relações de poder entre culturas tão diferentes, sendo uma delas julgada superior em relação às demais e em especial diante da cultura de enfermagem existente no estado, exercida por auxiliares e atendentes de enfermagem, julgada pelos superiores como uma Enfermagem elementar.

No processo de resistência as enfermeiras brasileiras souberam conduzir uma convivência pacífica, produtiva, aprendendo o que podiam aprender, mas afirmando a cultura de enfermagem brasileira que julgavam ser necessária imprimir neste novo espaço de exercício profissional da Enfermagem. 


\section{REFERÊNCIAS}

1. Santos RM. O navio HOPE: um novo encontro entre a enfermagem brasileira e a norte-americana. Maceió: Edufal; 2009.

2. Santos RM, Leite JL. A inserção da enfermagem moderna em Alagoas: os bastidores de uma conquista. Maceió: Edufal; 2004.

3. Elias N. O processo civilizador: formação do estado e civilização. Rio de Janeiro (RJ): Jorge Zahar; 1993.

4. Costa LMC, Santos RM, Trezza MCSF, Rozendo CA, Almeida LMWS. Produção de pesquisa histórica relativa à criação de cursos de graduação em enfermagem: uma revisão integrativa. Hist Enferm Rev Eletronica [Internet]. 2012 [acesso em 31 de janeiro de 2013];3(1):1-16. Disponível em: http://www.abennacional.org.br/centrodememoria/here/vol3num1artigo1.pdf

5. Santos RM, Tavares LVS, Cruz DE, Trezza MCSF. Circunstâncias de criação do Curso de Enfermagem da Universidade Federal de Alagoas: um estudo preliminar. Hist Enferm Rev Eletronica [Internet]. 2010 [acesso em 31 de janeiro de 2013];1(1):4. Disponível em: http://www.abennacional.org.br/centrodememoria/here/n1vol1ano1_artigo5.pdf

6. Elias N. O processo civilizador: uma história dos costumes. 2. ed. Rio de Janeiro (RJ): Jorge Zahar; 2011.

7. Durval C. Resumo Histórico da faculdade de Direito. In: Azevedo JF, coordenador. Universidade Federal de Alagoas: documentos históricos. Maceió: UFAL; 1982.

8. HOPE SS. Seminário: O processo de Enfermagem.
Maceió: Imprensa Universitária; 1973.

9. McEwen M, Wills EM. Bases Teóricas para Enfermagem. 2. ed. Porto Alegre: Artmed; 2009.

10. Figueiredo MCS, Mendonça MRA, Santos RM. Avaliação do curso de enfermagem e obstetrícia da Universidade Federal de Alagoas. Maceió (AL): EDUFAL; 1987.

11. Oliveira ON, Oliveira T. O processo civilizador segundo Norbert Elias. In: IX Seminário de Pesquisa em Educação da Região Sul - ANPED: a pós-graduação e suas interlocuções com a educação básica [Internet]. 2012; Caxias do Sul, Brasil [acesso em 31 de janeiro de 2013]. Disponível em: http://www.portalanpedsul. com.br/admin/uploads/2012/Historia_da_Educacao/ Trabalho/04_27_55_1342-6428-1-PB.pdf

12. Pereira LFL. Autoconsciência e processo civilizacional em Norbert Elias. Rev Relações Internacionais Mundo Atual [Internet]. 2002 [acesso em 31 de janeiro de 2013];(2):1946. Disponível em: http://revista.unicuritiba.edu.br/index.php/RIMA/article/view/218/191

13. Ferreira RA. O conceito de redes de interação social aplicado à gestão escolar: uma leitura a partir das contribuições de Norbert Elias. In: XXV Simpósio Brasileiro, II Congresso Ibero-Americano de Política e Administração da Educação Jubileu de Ouro da ANPAE (1961-2011) [Internet]. 2011 abr 26-29; São Paulo, Brasil [acesso em 31 de janeiro de 2013]. Disponível em: http://www.anpae. org.br/simposio2011/cdrom2011/PDFs/trabalhosCompletos/comunicacoesRelatos/0478.pdf 